\title{
Article \\ A Lipid Bodies-Associated Galactosyl Hydrolase Is Involved in Triacylglycerol Biosynthesis and Galactolipid Turnover in the Unicellular Green Alga Chlamydomonas reinhardtii
}

\author{
Xiaosong Gu ${ }^{1,2}{ }^{\oplus}$, $\mathrm{Li} \mathrm{Cao}^{1}{ }^{1}$, Xiaoying $\mathrm{Wu}^{1}{ }^{1}$, Yanhua $\mathrm{Li}^{1}$, Qiang $\mathrm{Hu}{ }^{1,3,4,5}$ and Danxiang Han ${ }^{1, *}$ \\ 1 Center for Microalgal Biotechnology and Biofuels, Institute of Hydrobiology, Chinese Academy of Sciences, \\ Wuhan 430072, China; xiaosonggu@ihb.ac.cn (X.G.); licao@ihb.ac.cn (L.C.); xiaoyingw@163.com (X.W.); \\ yanhuali@ihb.ac.cn (Y.L.); huqiang@ihb.ac.cn (Q.H.) \\ 2 College of Life Sciences, University of Chinese Academy of Sciences, Beijing 100049, China \\ 3 Institute for Advanced Study, Shenzhen University, Shenzhen 518060, China \\ 4 Key Laboratory for Algal Biology, Institute of Hydrobiology, Chinese Academy of Sciences, \\ Wuhan 430072, China \\ 5 State Key Laboratory of Freshwater Ecology and Biotechnology, Institute of Hydrobiology, Chinese Academy \\ of Sciences, Wuhan 430072, China \\ * Correspondence: danxianghan@ihb.ac.cn
}

Citation: Gu, X.; Cao, L.; Wu, X.; Li, Y.; Hu, Q.; Han, D. A Lipid Bodies-Associated Galactosyl Hydrolase Is Involved in Triacylglycerol Biosynthesis and Galactolipid Turnover in the Unicellular Green Alga Chlamydomonas reinhardtii. Plants 2021, 10, 675. https://doi.org/10.3390/ plants10040675

Academic Editor: José Manuel Martínez-Rivas

Received: 16 February 2021

Accepted: 29 March 2021

Published: 31 March 2021

Publisher's Note: MDPI stays neutral with regard to jurisdictional claims in published maps and institutional affiliations.

Copyright: (c) 2021 by the authors. Licensee MDPI, Basel, Switzerland. This article is an open access article distributed under the terms and conditions of the Creative Commons Attribution (CC BY) license (https:/ / creativecommons.org/licenses/by/ $4.0 /)$.

\begin{abstract}
Monogalactosyldiacylglycerol (MGDG) and digalactosyldiacylglycerol (DGDG) are the main constituent lipids of thylakoid and chloroplast envelop membranes. Many microalgae can accumulate large amounts of triacylglycerols (TAGs) under adverse environmental conditions, which is accompanied by degradation of the photosynthetic membrane lipids. However, the process mediating the conversion from galactolipids to TAG remains largely unknown. In this study, we performed genetic and biochemical analyses of galactosyl hydrolases $(\mathrm{CrGH})$ identified in the proteome of lipid bodies of the green microalga Chlamydomonas reinhardtii. The recombinant $\mathrm{CrGH}$ was confirmed to possess galactosyl hydrolase activity by using o-nitrophenyl- $\beta$-D-galactoside as the substrate, and the Michaelis constant $(\mathrm{Km})$ and Kcat of $\mathrm{CrGH}$ were $13.98 \mu \mathrm{M}$ and $3.62 \mathrm{~s}^{-1}$, respectively. Comparative lipidomic analyses showed that the content of MGDG and DGDG increased by $14.42 \%$ and $24.88 \%$, respectively, in the $\mathrm{CrGH}$-deficient mutant as compared with that of the wild type cc4533 grown under high light stress conditions, and meanwhile, the TAG content decreased by $32.20 \%$. Up-regulation of $\mathrm{CrGH}$ at both a gene expression and protein level was observed under high light stress (HL) conditions. In addition, $\mathrm{CrGH}$ was detected in multiple subcellular localizations, including the chloroplast envelope, mitochondria, and endoplasmic reticulum membranes. This study uncovered a new paradigm mediated by the multi-localized $\mathrm{CrGH}$ for the conversion of the photosynthetic membranes to TAGs.
\end{abstract}

Keywords: Chlamydomonas reinhardtii; galactosyl hydrolase; galactolipids; triacylglycerol

\section{Introduction}

Microalgal biomass can be utilized as a feedstock for producing biofuels, owing to its high lipid contents [1,2]. Understanding the process of lipid biosynthesis is essential for the engineering of microalgae for improving lipid production. The unicellular green alga Chlamydomonas reinhardtii has been used as a model organism for studying lipid metabolism [3,4]. Like many other microalgae, the C. reinhardtii cells can accumulate triacylglycerols (TAGs) when subjected to adverse environmental conditions such as high light and nutrient starvation [2,5]. There are two TAG biosynthesis pathways that have been identified in C. reinhardtii [6], the acyl-CoA-dependent pathway and acyl-CoAindependent pathway [4,7-9]. The acyl-CoA-dependent pathway involves three sequential acylation reactions and one dephosphorylation reaction [10]. Currently, two glycerol-3phosphate: acyl-CoA acyltransferase encoding genes (i.e., CrGPATer and CrGPATcl) [11], 
two lyso-phosphatidic acid: acyl-CoA acyltransferase encoding genes (i.e., CrLPAAT1 and CrLPAAT2) [12,13], and six diacylglycerol: acyl-CoA acyltransferase encoding genes (i.e., DGAT1 and DGTT1- to -DGTT5) have been identified in C. reinhardtii $[4,7,8]$. The acylCoA-independent pathway in C. reinhardtii is mediated by an ortholog of phospholipid: diacylglycerol acyltransferase (PDAT) gene [9].

Galactolipids are the constitutive lipids of the thylakoid membranes of higher plants, as well as microalgae [14]. Monogalactosyldiacylglycerol (MGDG) and digalactosyldiacylglycerol (DGDG) are two major galactolipids, accounting for about $50 \%$ and $30 \%$ of thylakoid membrane lipids, respectively [15]. Crystallization studies have shown that MGDG and DGDG are the integral components of PSI [16], PSII [17-19], and cytochrome $b 6 f$ complex [20,21], which are essential for the assembly and function of the photosynthetic apparatus [22-24]. TAG accumulation in microalgae under adverse stress conditions is usually accompanied by degradation of the photosynthetic membrane lipids, particularly for galactolipids [7,9]. Transmission electron microscopic observation revealed that the stacked thylakoid membranes were dramatically degraded when the $C$. reinhadtii cells accumulated TAG under nitrogen deprivation conditions [25]. Lipidomics analysis indicated that the cellular content of MGDG declined by $63 \%$, while TAG increased around 40 times over two days under nitrogen deprivation [9].

Recently, a number of genes involved in galactolipid turnover have been identified in microalgae and plants. For example, disrupting a MGDG-specific lipase PGD1 (plastid galactolipid degradation 1) in C. reinhardtii resulted in a 50\% decrease in TAG content, which suggested that the fatty acids utilized for TAG biosynthesis were at least partially recycled from MGDG [26]. The PDAT pathway contributed to approximately $25 \%$ of the total TAG accumulated in C. reinhardtii under nitrogen deprivation conditions [7], and the in vitro acyltransferase assay indicated that the PDAT of $C$. reinhardtii can utilize MGDG as the acyl donor and DAG as the acceptor for producing TAG [9]. Studies on Arabidopsis thaliana have suggested that the gene SENSITIVE TO FREEZING 2 (AtSFR2) coded for a galactolipid, galactolipid galactosyltransferase (GGGT), which transfers the galactosyl moieties from MGDG onto a variety of galactolipid receptors to generate oligogalactolipids (i.e., di-, tri- or tetragalactosyldiacylglycerol) and DAG [27]. However, no ortholog of SFR2 has been identified in the unicellular algae, including C. reinhardtii [28], suggesting that more unicellular algae-specific genes/pathways involved in the turnover of galactolipids remain to be identified.

In microalgae, the TAGs synthesized under stress conditions are stored in lipid bodies (LBs), which contained a hydrophobic core surrounded by a polar lipid monolayer coated with proteins [29]. Numerous proteins involved in a variety of functions including lipid metabolism have been identified in the lipid bodies-enriched fraction of $C$. reinhardtii through proteomics analysis [25,30-32]. For example, functional classification showed that 58 proteins detected in Chlamydomonas LBs fraction were involved in lipid metabolism, including GPAT, LPAAT, and PDAT, which accounted for $9 \%$ of the total number of LB proteins. Moreover, several proteins putatively involved in deacylation/reacylation, lipid signaling and lipid trafficking (i.e., TGD1, TGD2, and TGD) were also found to be associated with the LB fraction [32]. Interestingly, it was revealed that the DGDG was present as one of the major membrane lipids in the LBs [33], indicating that the galactolipids might be transported to LBs and then converted to the storage lipids in situ. Thus, dissecting the proteomics of LBs may allow us to identify the novel gene responsible for converting galactolipids to TAG.

To this end, data mining was performed on a previously-reported proteome of Chlamydomonas LBs [25], leading to the identification of a putative glycosyl hydrolase (GH) with high abundance. In this study, the LB-associated GH encoding gene was cloned and characterized. By using the purified recombinant protein, the galactosyl hydrolase activity of $\mathrm{CrGH}$ was confirmed. A lipidomics analysis performed on the $\mathrm{Cr} \mathrm{GH}$-defective mutant provided lines of evidence supporting the in vivo functions of $\mathrm{CrGH}$ being involved in TAG biosynthesis and galactolipids turnover. 


\section{Results}

\subsection{Identification of a Glycosyl Hydrolase Gene from C. reinhardtii}

A putative glycosyl hydrolase gene (accession number Cre03.g171100.t1.1, designated as $\mathrm{Cr} G H$ ) was identified when conducting a BLASTP search in the $C$. reinhardtii genome database by using the reported LB-associated glycosyl hydrolase protein sequence (Chlre V 3.0 Protein ID:169029) as the query. The 1527-bp open reading frame of $\mathrm{CrGH}$ was amplified (Figure 1a), and the amino acid sequences showed $100 \%$ similarity with the LB-associated glycosyl hydrolase. CrGH belongs to the glycosyl hydrolase family 1, with the conserved active sites (TFNEP and ITETG) (Figure 1b,c), and similar to the structure of glycosyl hydrolase from Oryza sativa (OsGH, GenBank: AKS44051), it possesses the representative triosephosphate isomerase (TIM) barrel consisting of eight $\alpha$-helices and eight parallel $\beta$-strands.

a

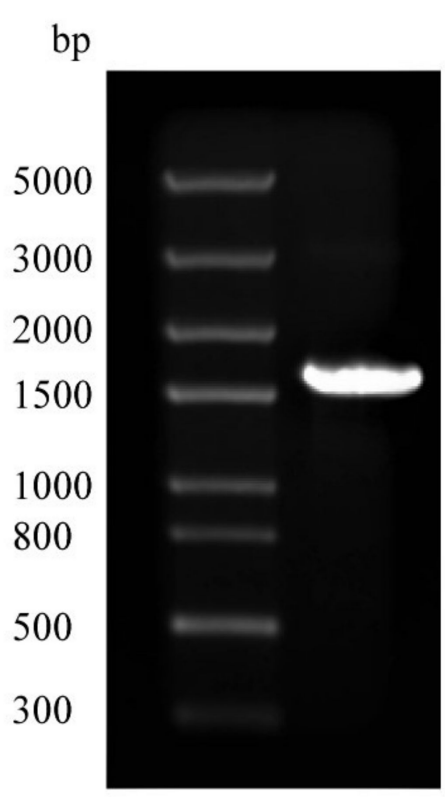

b

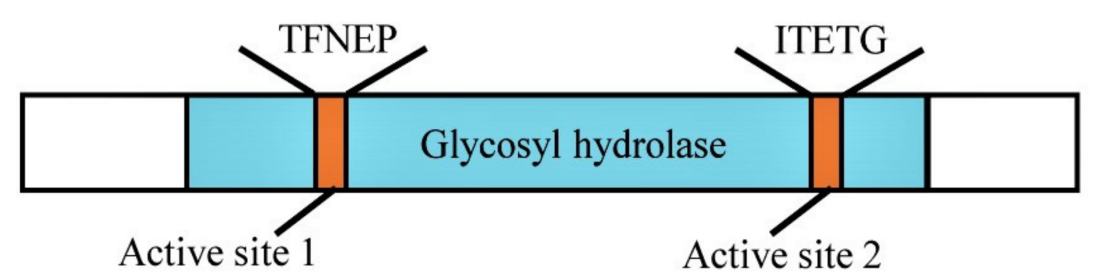

c

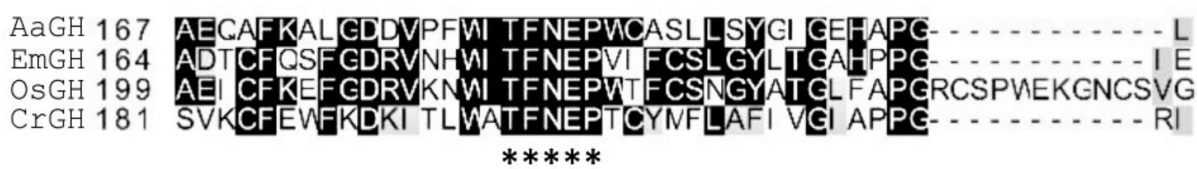

AaGH 337

EmGH 350

OsGH 390

CrGH 343

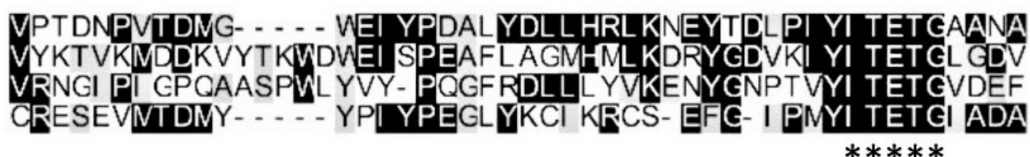

Figure 1. Cloning of the galactosyl hydrolase gene from Chlamydomonas reinhardtii and bioinformatics analysis. (a). The PCR amplification of $\mathrm{CrGH}(\sim 1527 \mathrm{bp})$. (b). Functional domains of the putative $\mathrm{CrGH}$, which consists of active sites (turquoise boxes) and glycosyl hydrolase domain (orange box). (c). Multiple protein sequence alignment of glycosyl hydrolases of Alicyclobacillus acidiphilus (AaGH, accession number: WP_067621817.1), Exiguobacterium marinum (EmGH, accession number: WP_026824377.1), Oryza sativa (OsGH, accession number: 3PTQ_B), and C. reinhardtii (CrGH, GenBank: Cre03.g171050.t1.1). The sites of the active site peptide motifs (TFNEP and ITETG) are indicated $\left(^{*}\right.$ ).

The purified recombinant CrGH were approximately 98 kDa (Figure 2a), consistent with the predicted molecular size. The galactosyl hydrolase activity of $\mathrm{CrGH}$ was measured by using o-nitrophenyl- $\beta$-D-galactoside (ONPG) as the substrate. The results showed that the recombinant $\mathrm{CrGH}$ possessed galactosyl hydrolase activities, which can release the o-nitrophenol from ONPG, and the enzymatic activities were positively correlated with the concentration of the enzymes (Figure $2 b, c$ ). In addition, the enzymatic kinetics of the galactosyl hydrolase assay in vitro showed that the Michaelis constant $(\mathrm{Km})$ of $\mathrm{CrGH}$ was $13.98 \mu \mathrm{M}$ and the Kcat was $3.62 \mathrm{~s}^{-1}$ (Figure $2 \mathrm{~d}$ ).

\subsection{CrGH Is Involved in TAG Synthesis and Galactolipids Turnover}

The enzymatic activity of $\mathrm{CrGH}$ in vitro suggested that it might be involved in converting galactolipids into DAG and then into TAG in C. reinhardtii. To test this hypothesis, a candidate $\mathrm{CrGH}$-insertion mutant (LMJ.RY0402.088610) was obtained from the genomewide insertion library of $C$. reinhardtii mutants for in vivo functional characterization. The gene expression analysis results showed that $C r G H$ mRNA abundance significantly de- 
creased, by $92 \%$, in mutant 08 compared with that of the wild strain cc4533 (Figure 3a), and $\mathrm{CrGH}$ was undetectable in mutant 08 under a N-replete condition (Figure 3b). Moreover, the genome-cassette junctions PCR-based characterization of the insertion sites was performed as shown in the schematic diagram (Figure 3c). The sequencing analysis of the resulting PCR products indicated that the insertion sites were located in the intron of CrGH genomic DNA locus (Figure 3d). Based on these results, LMJ.RY0402.088610 was identified as the $\mathrm{CrGH}$-deficient mutant. As shown in Figure S1, the cellular growth was not affected by deficiency in $\mathrm{CrGH}$ under the low light (LL), whereas the growth rate was slightly retarded in the mutant08 grown under high light stress (HL) as compared to the wild type.

a

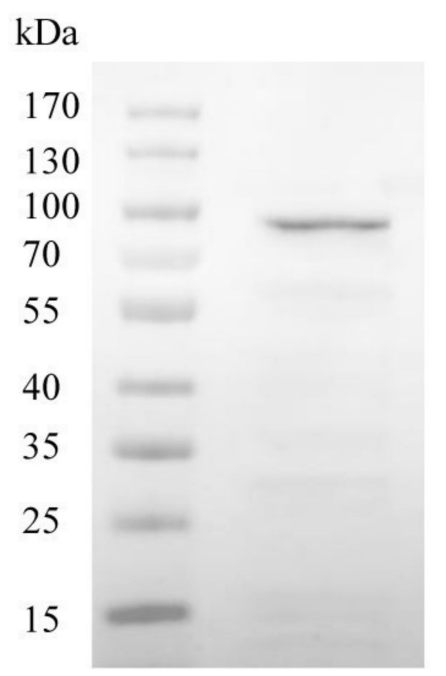

b

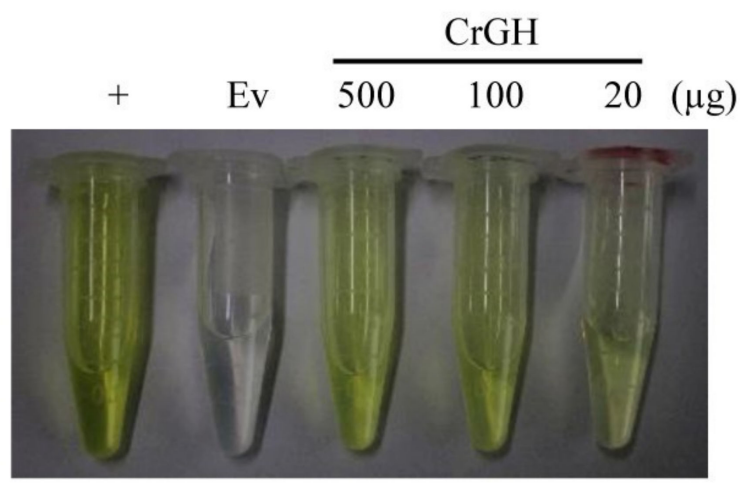

$\mathrm{c}$

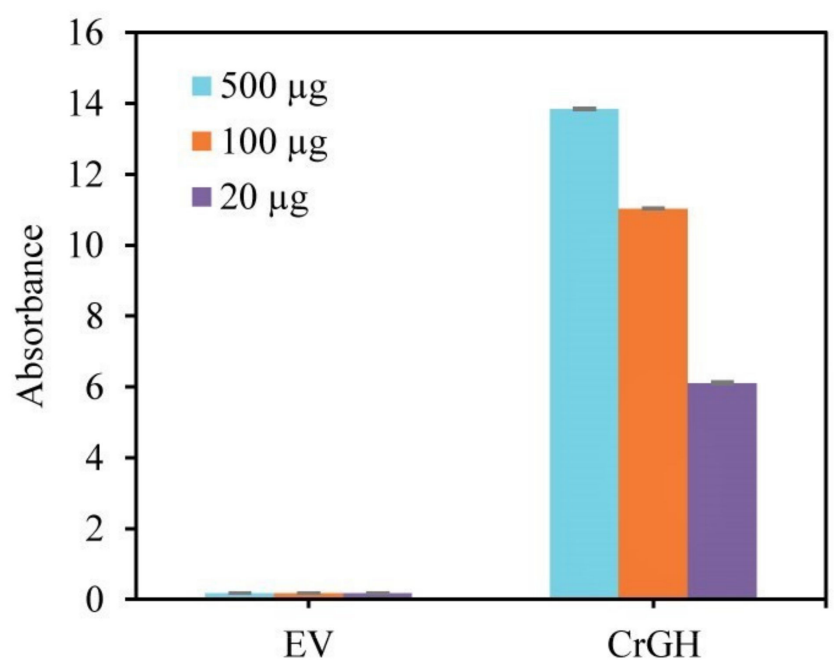

$\mathrm{d}$

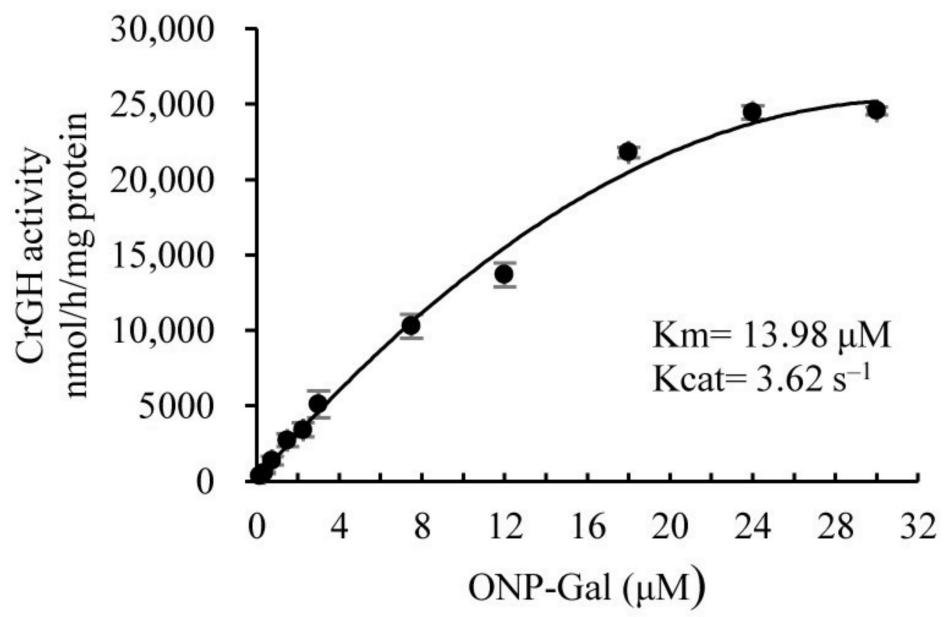

Figure 2. In vitro assay of the galactosyl hydrolase activity for the recombinant CrGH. (a). Expression of the recombinant $\mathrm{CrGH}$ in E. coli. (b). Enzymatic assay for $\mathrm{CrGH}$ with the substrate of ONP- $\beta$-D-galactopyranoside. EV, empty vector. The $\beta$ - galactosidase from $E$. coli was used in the enzymatic reactions as a positive control. (c). Quantitation of the produced o-nitrophenol in enzymatic assays with various quantities of $\mathrm{CrGH}$. (d). Kinetic determination of galactosyl hydrolase of the recombinant $\mathrm{CrGH}$. 
a

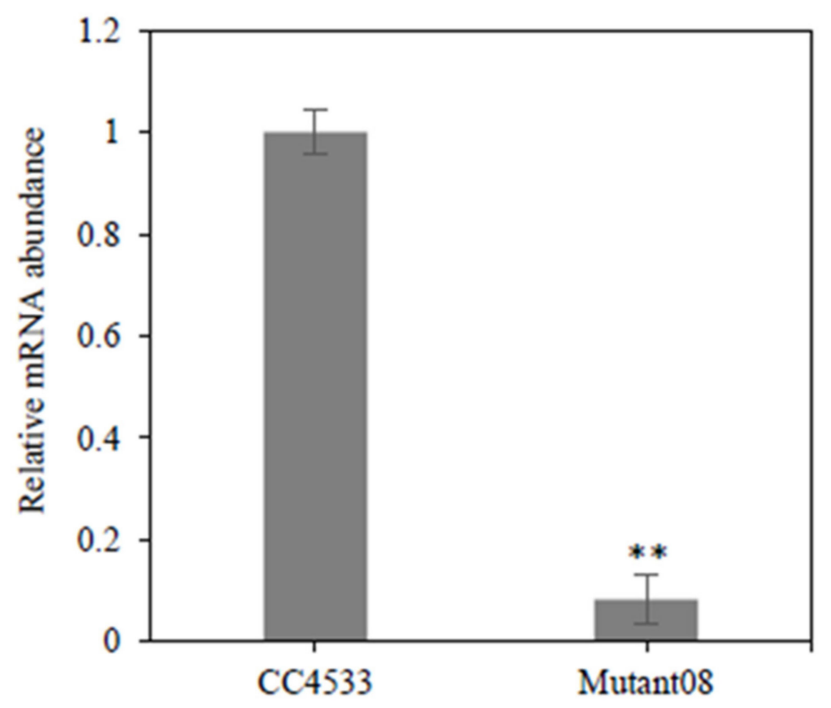

$\mathrm{b}$

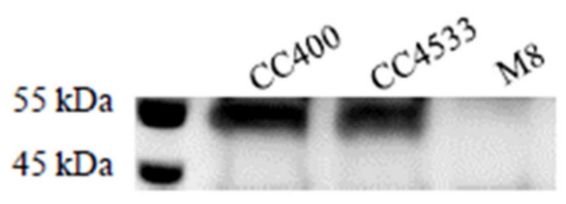

c
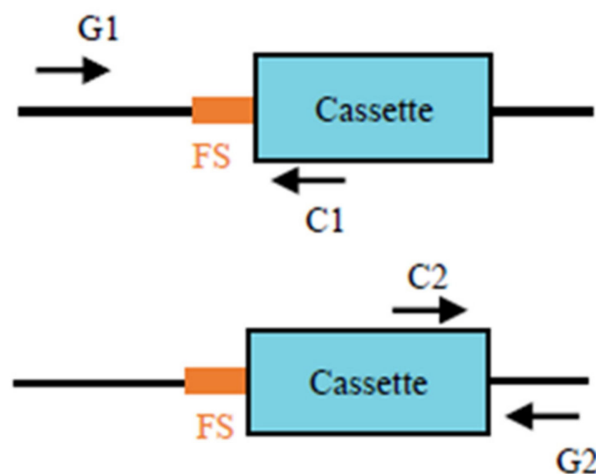

d

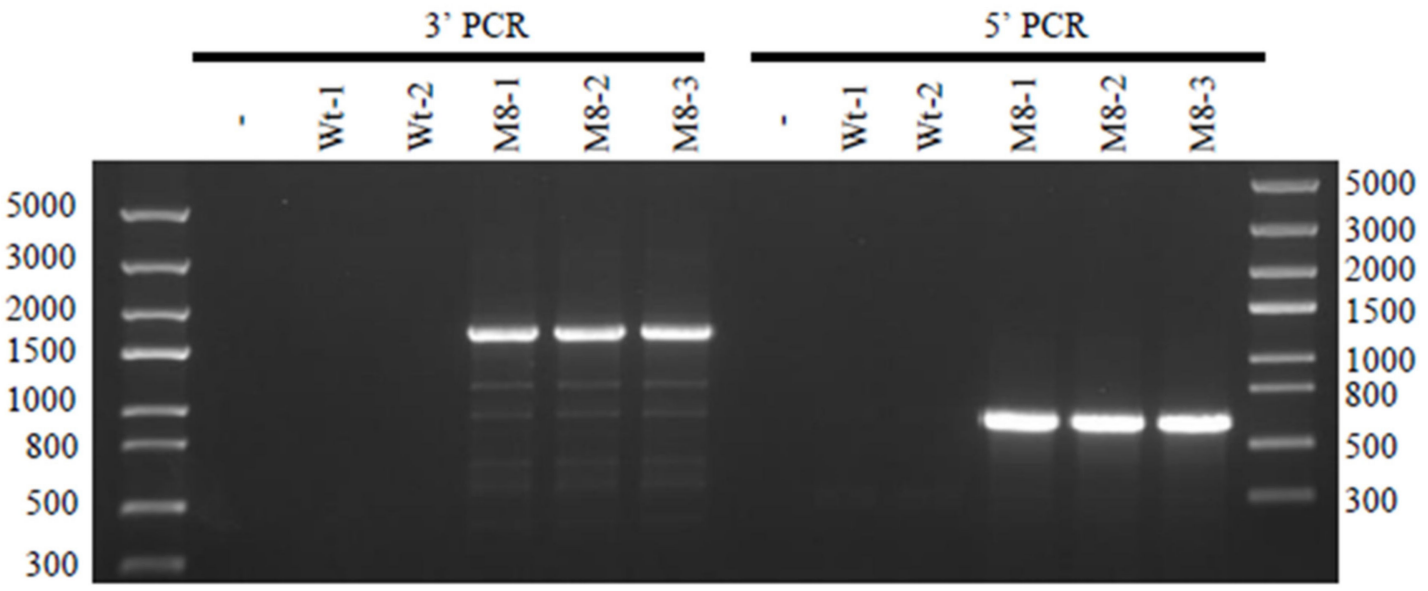

Figure 3. Verification of the insertion in $\mathrm{CrGH}$. (a). Relative level of the $\mathrm{CrGH}$ mRNA transcript by real-time fluorescent quantitative PCR. The abundance of mRNA was normalized to the mRNA transcript level in wild type cc4533 strain, which was set as 1. Data are presented as average $\pm \mathrm{SD}(\mathrm{n}=3)^{*} p<0.05,{ }^{* *} p<0.01$. (b). Immunoblotting analysis of the protein levels of $\mathrm{CrGH}$ in the wild type (cc4533 and cc400) and mutant08 strains. Twenty micrograms of the whole-cell proteins were loaded in each lane. (c). Schematic diagram of genome-cassette junction amplification. The flanking DNA sequences (FS) were amplified with PCR primers binding to the cassette and genome. (d). Amplification of genome-cassette with the locus disruption. The resulting PCR product was sequenced for identifying the site of each insertion.

Lipidomics analysis of TAG showed that there was no significant difference in TAG content between the mutant08 and the wild type cc4533 under the LL, whereas the TAG in mutant08 was considerably reduced by $32.20 \%$ at 96 h compared to that of the wild type cc4533 strain under the HL (Figure 4a). Under LL conditions, as compared with that of the wild type, the fatty acid profile of TAG in mutant08 showed a $55.09 \%$ and $75.80 \%$ decrease in the 16:0 and C18:1 (n9c), while 69.34\%, 87.44\%, and 1.24-fold increases were observed in the C18:2 (n6t), C18:2 (n6c), and C18:3 (n6), respectively. Under HL conditions, the percentage of two monounsaturated fatty acids, $16: 1$ and $18: 1$, was reduced by $64.66 \%$ and $88.09 \%$ in the mutant08, respectively. Meanwhile, the percentage of the polyunsaturated fatty acids C18:2 (n6t), C18:2 (n6c), and C18:4 increased by 3.47 and 1.31 times, and 20.00\%, respectively (Figure $4 b$ ). 

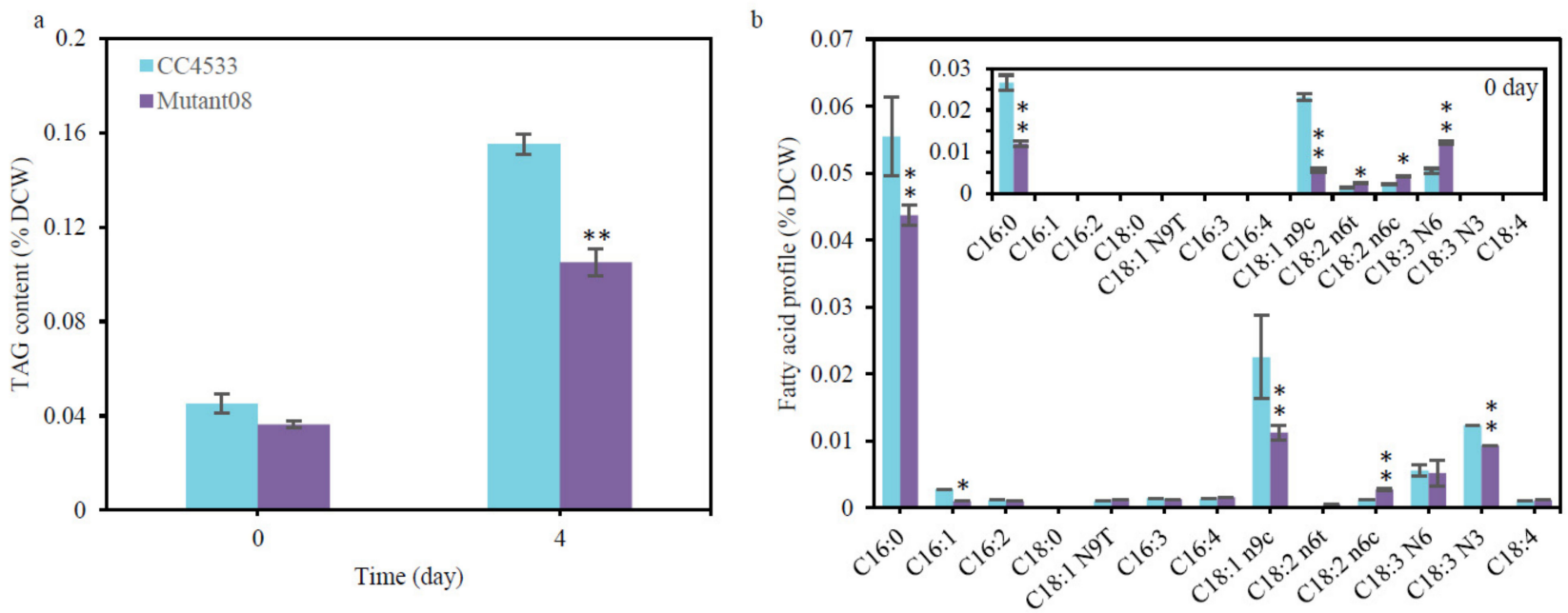

c

d
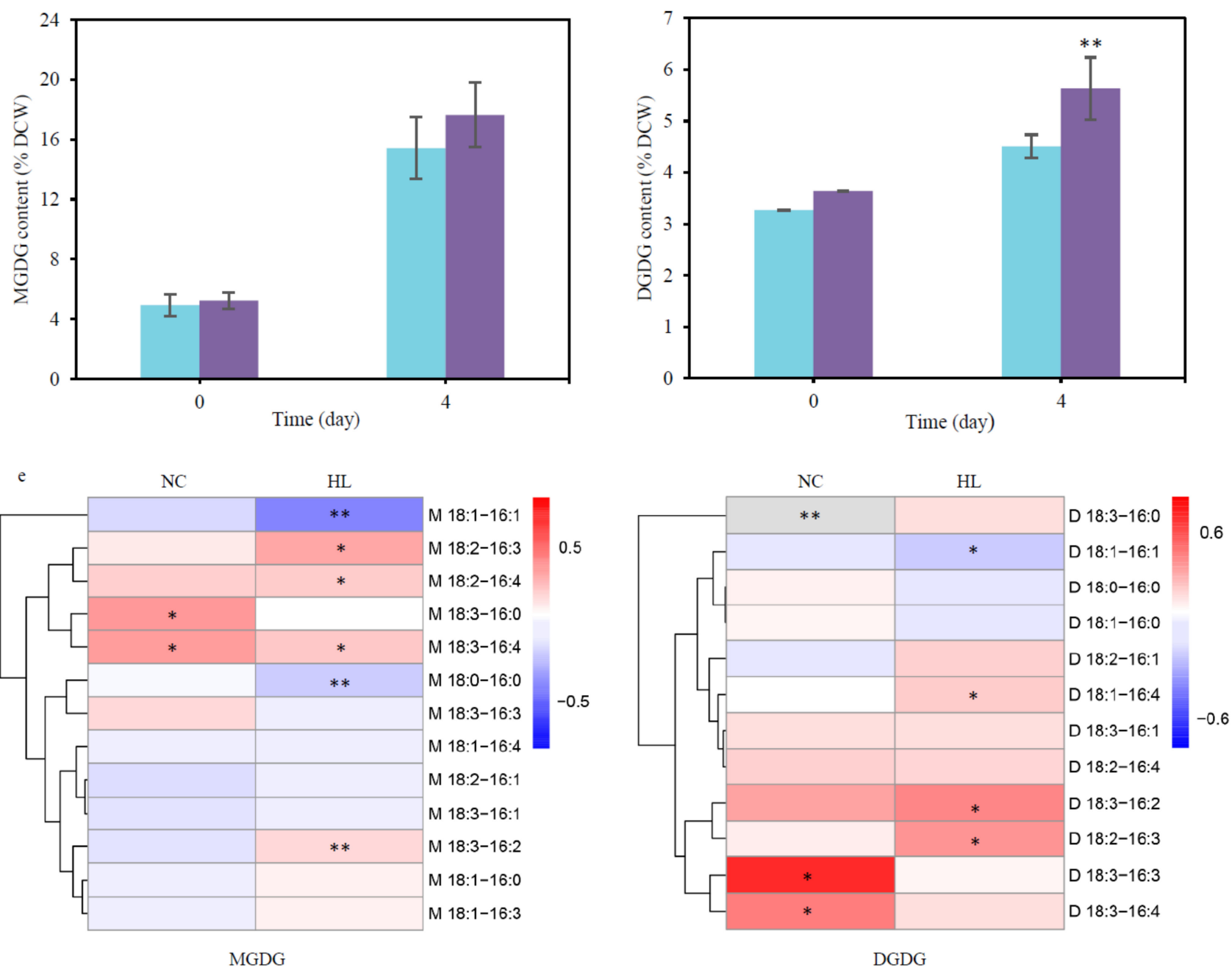

Figure 4. Insertional mutation of $\mathrm{CrGH}$ suppressed TAG accumulation and resulted in increases in the contents of galactolipids. (a). TAG contents of the wild type cc 4533 and mutant 08 grown under low light (LL) (day 0 ) and high light stress (HL) (day 4). (b). Fatty acid profile of the TAG. (c). Monogalactosyldiacylglycerol content. (d). Digalactosyldiacylglycerol content of the wild type cc 4533 and mutant08 grown under LL (day 0) and HL (day 4). (e). Heatmap of the fold-changes in the galactolipids content in mutant 08 as compared with that of the wild type cc4533. Fold-changes were calculated as $\log _{10}(\mathrm{C}(\mathrm{Tx}, \mathrm{M} 8) / \mathrm{C}(\mathrm{Tx}, \mathrm{wt})) . \mathrm{C}_{\mathrm{M} 8}$ and $\mathrm{C}_{\mathrm{wt}}$ represent the contents of galactolipids in mutant08 and wild type cc4533 strains, respectively. Tx is time point. Data are presented as average $\pm \operatorname{SD}(n=3) .{ }^{*} p<0.05,{ }^{* *} p<0.01$. 
To test whether CrGH could utilize galactolipids as the substrate in vivo, the cellular contents of the MGDG and DGDG in the wild type cc4533 and mutant08 strains were quantitatively analyzed by ESI/MS. Under the LL conditions, there was no significant difference in the total contents of MGDG and DGDG between the mutant08 and the wild type cc4533 (Figure 4c,d). Under HL conditions, the contents of MGDG and DGDG in mutant 08 increased by $14.42 \%$ and $24.88 \%$ at $96 \mathrm{~h}$, respectively, as compared to that of the wild type cc4533 (Figure 4c,d). The contents of a number of MGDG and DGDG molecules were significantly altered in the mutant08. Under LL conditions, the content of MGDG 18:3-16:0, MGDG 18:3-16:4, DGDG 18:3-16:3, and DGDG 18:3-16:4 increased by 35.73\%, $34.10 \%, 51.89 \%$, and $33.26 \%$, respectively, in the mutant 08 as compared to that of the wild type cc4533 (Figure 4e), though no significant change was detected in the contents of the total galactolipids. Under HL conditions, the content of MGDG 18:2-16:3, MGDG 18:2-16:4, MGDG 18:3-16:4, and MGDG 18:3-16:2 was elevated by $31.65 \%, 20.92 \%, 21.01 \%$, and $16.73 \%$, respectively. At the same time, the DGDG species increased to a greater extent than the MGDG species, among which DGDG 18:1-16:4, DGDG 18:3-16:2, and DGDG $18: 2-16: 3$ increased by $16.16 \%, 31.86 \%$, and $28.96 \%$ in the mutant 08 as compared to that of wild type cc4533 (Figure 4e). On the other hand, no significant change was detected in the contents of the major extraplastidic membrane lipid DGTS and phosphatidylethanolamine (PtdEtn) between the wild type cc4533 and the mutant08 strains under both LL and HL conditions (Figure S2), suggesting that $\mathrm{CrGH}$ was mainly involved in galactolipids metabolism rather than other extraplastidic membrane lipids in C. reinhardtii. These results taken together indicated that $\mathrm{CrGH}$ might be involved in the remodeling of galactolipids for TAG biosynthesis under HL stress conditions, and it was more likely that CrGH preferred to use the galactolipids with the polyunsaturated fatty acid side chains as the substrates.

\subsection{Responses of CrGH to HL Stresses and its Subcellular Localization}

To confirm whether $\mathrm{CrGH}$ was involved in high-light stress responses in C. reinhardtii cells, the gene expression was analyzed by quantitative real-time PCR. There was no change in the relative mRNA level in the wild type cc400 cells under the LL conditions, while the transcription of $\mathrm{CrGH}$ was transiently up-regulated to the maximum level that corresponded to 3.75 times of the control at $6 \mathrm{~h}$ under HL. After $12 \mathrm{~h}$, the transcripts of $\mathrm{CrGH}$ were reduced rapidly to the same levels as the control at $24 \mathrm{~h}$, and then subsequently increased by 2.08 times at $72 \mathrm{~h}$ (Figure $5 \mathrm{a}$ ). At the protein level, there was no significant difference between the mutant08 and the wild type cc4533 under the LL. Under the HL, the abundance of $\mathrm{CrGH}$ increased slightly at $6 \mathrm{~h}$ and $12 \mathrm{~h}$, reaching 1.41 and 1.48 times of the control, respectively. Subsequently, the abundance of $\mathrm{CrGH}$ reduced initial level as the control at $24 \mathrm{~h}$, while at $48 \mathrm{~h}$ and $72 \mathrm{~h}$ it was up-regulated 1.47 and 1.54 times, respectively (Figure 5 b).

Bioinformatic analysis with the online prediction tool ChloroP 1.1, SignalP 4.0, TargetP 1.1, WoLF PSORT, and ProtComp initially failed to predict the subcellular localization of $\mathrm{CrGH}$. The targetP 1.1 prediction analysis showed that the scores of CTP and mTP were 0.192 and 0.134 with the reliability class of 2 , respectively, which indicated that $\mathrm{CrGH}$ might be a dual-targeting protein. The ProtComp integral prediction of protein location showed that the scores of the prediction in extracellular, cytoplasmic, mitochondrial, peroxisomal, and chloroplast were $2.36,1.73,1.25,2.18$, and 1.39 , respectively, but no significant similarity was indicated by DBSCAN-P test. In addition, the localizations predicted by comparing the query sequence with its homologs with WoLF PSORT were ambiguous (Table S2). To resolve the subcellular localization of $\mathrm{CrGH}$, the fractions of chloroplast envelope, mitochondria, endoplasmic reticulum, and thylakoid membranes were isolated from the whole-cell lysates of cc400 cells. Immunoblotting analysis by using the antisera against the marker proteins for each subcellular compartment indicated that high-quality subcellular compartments were obtained (Figure 5c). When using these subcellular compartments for analyzing the subcellular localization of $\mathrm{CrGH}$, it was detected in the chloroplast envelope, 
mitochondria, and endoplasmic reticulum fractions. These results suggested that $\mathrm{CrGH}$ was a multi-localization targeting protein in C. reinhardtii cells.

a

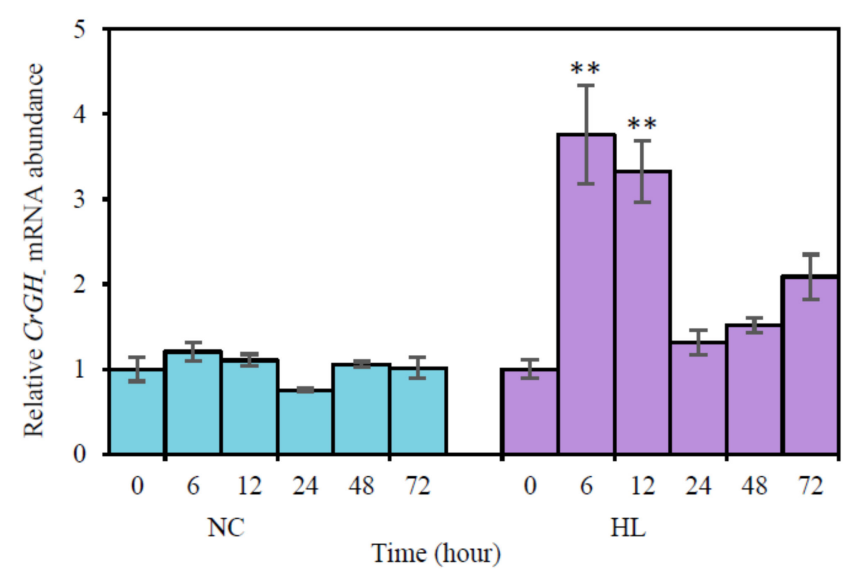

c

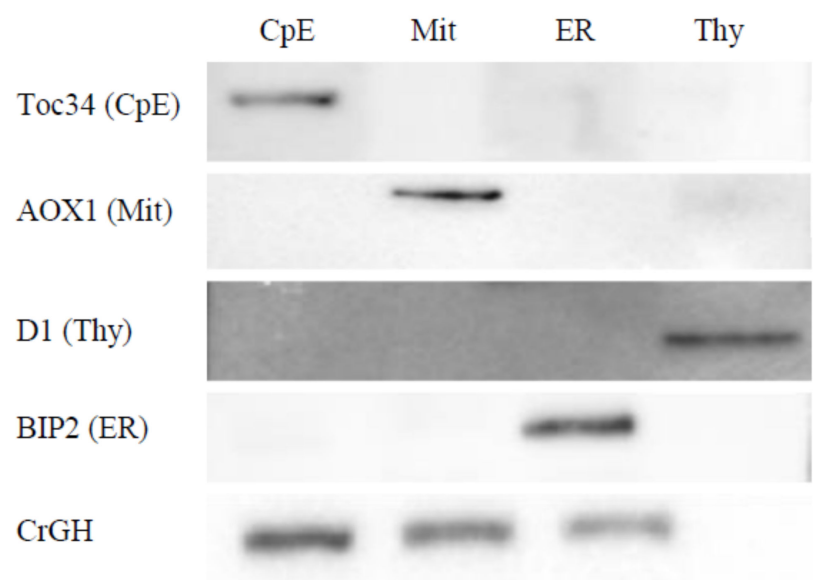

$\mathrm{b}$
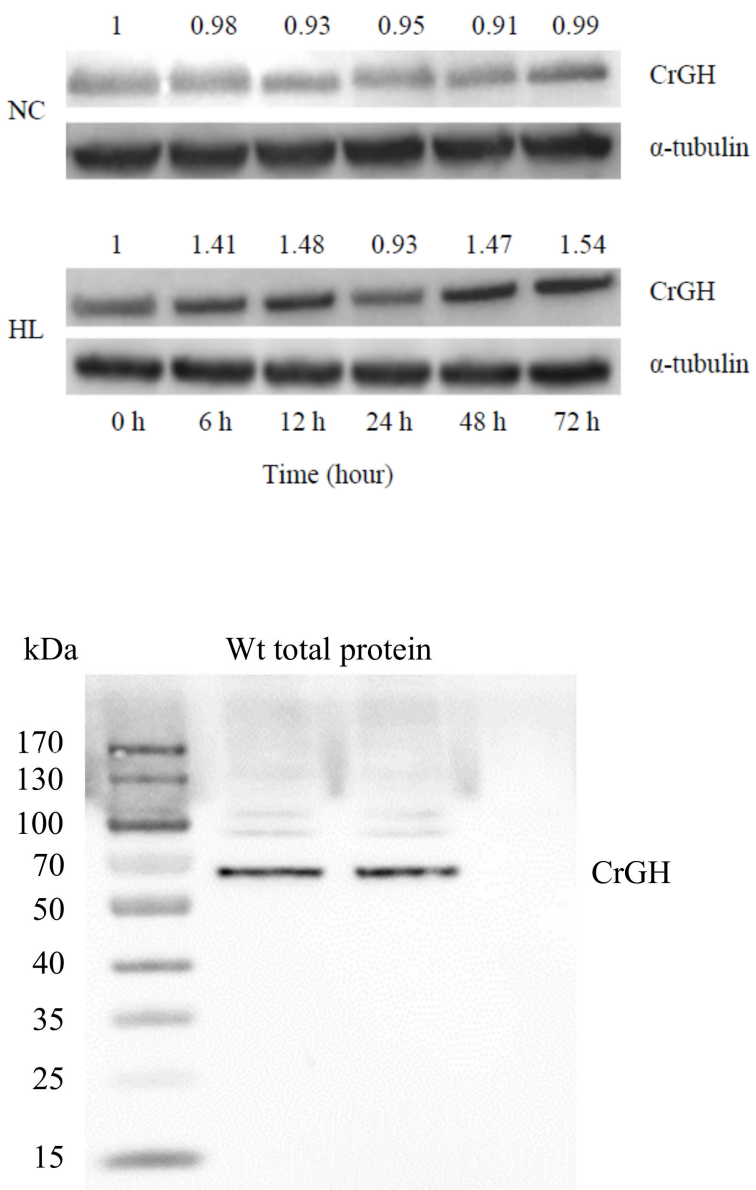

Figure 5. Up-regulation of $\mathrm{CrGH}$ under high light stress (HL) conditions and multi-localization of CrGH. (a). CrGH mRNA levels in wild type cc400. cells under the normal culture (NC) and high light stress conditions (HL). The abundance of mRNA was normalized to the $\mathrm{CrGH}$ mRNA level in cc400 at $0 \mathrm{~h}$, which was set as 1 . Data are presented as average $\pm \mathrm{SD}$ $(\mathrm{n}=3)$, which the asterisks * indicates that the $p$ value of significance is less than 0.05 , and ** indicates that the $p$ value of significance is less than 0.01. (b). CrGH protein expression levels in cc400 cells, as determined by immunoblot analysis. Protein concentration was normalized to the $\mathrm{CrGH}$ expression level in cc400 at $0 \mathrm{~h}$, which was set as 1 . The $\alpha$-tubulin gene was used as a reference control. (c). Subcellular localization of $\mathrm{CrGH}$ in C. reinhardtii. CpE, chloroplast envelope; Mit, mitochondria; ER, endoplasmic reticulum; Thy, thylakoid membrane; Wt total protein, the total protein from the wild type cc400 strain. Toc34, AOX1, D1, and BIP2 were used as markers for the CpE, Mit, Thy, and ER, respectively.

\section{Discussion}

TAG and galactolipid metabolism are believed to be closely interactive in microalgae $[6,9,34]$. As the major components of the photosynthetic membranes, galactolipids are subjected to photo-oxidative stresses under various adverse environmental conditions. Biosynthesis of TAG molecules can sequester excess electrons from the photosynthetic electron transport chain for reducing the oxidative damage to photosystems [2]. A previous study showed that disrupting the galactolipid lipase encoding gene PGD1 in C. reinhardtii resulted in a 50\% decrease of the TAG content and chlorotic appearance during nitrogen deprivation. As a result, over-reduction of the photosynthetic electron transport chain caused severe damage to thylakoid membranes and led to the cell death for the mutant [26]. In this study, the results of in vitro and in vivo analyses taken together indicated that $\mathrm{CrGH}$ 
is a galactosyl hydrolase involved in TAG biosynthesis and galactolipids degradation under HL stress. Indeed, it represents a new paradigm in which the most abundant photosynthetic membrane lipids could be converted to DAG through hydrolysis of the galactose residue and then be utilized for TAG biosynthesis. Moreover, nitrogen deprivation is an important stress treatment to induce the TAG accumulation in Chlamydomonas reinhardtii. Therefore, we are investigating whether the $\mathrm{CrGH}$ is involved in converting galactolipids into the TAG under $\mathrm{N}$-deprivation conditions and other abiotic stress conditions, such as high salinity, and the experiments are underway.

Under HL stress, the cone-like shaped MGDG tends to form an inverted hexagonal phase (HII) [35], which can cause the fusion of photosynthetic membranes, and is thus deleterious for photosynthetic cells. However, the $\mathrm{CrGH}$ deficient mutant did not show any defect in growth under HL stress (Figure S1). It is noteworthy that only a few MGDG species showed a slight increase in the mutant, while the changes in the DGDG content were more substantial than that of MGDG. In addition, $\mathrm{CrGH}$ was detected in both the chloroplast envelope and the extraplastidic compartments, including mitochondria and endoplasmic reticulum. Based on these observations, we speculated that it was most likely that $\mathrm{CrGH}$ mainly acted on DGDG, instead of MGDG. DGDG is a type of typical bilayer lipid that has been identified in multiple subcellular compartment membranes, in addition to the chloroplasts of plant cells, including mitochondria and plasma membranes [36]. A previous study showed that DGDG was present on the surface of LBs in C. reinhardtii cells [33], suggesting that DGDG can be exported from the chloroplasts to extraplastidic organelles when algal cells accumulate enormous amounts of TAGs. In addition, there are extensive lines of evidence showing that LBs interact with a variety of cell organelles, including the endoplasmic reticulum, mitochondria, chloroplast, and peroxisomes, presumably via the membrane contact sites $[28,37,38]$.

In this study, we failed to detect the formation of galactose when commercial and purified galactolipids of $C$. reinhardtii were used as the substrates to test the enzymatic activity of the recombinant $\mathrm{CrGH}$ (data not shown). This could be attributable to the alterations in conformation of the membrane-bound galactolipids in solvents. The MGDG bilayer formation requires the participation of the relative proteins, but after extraction form C. reinhardtii, it may form a hexagonal (HII) non-lipid bilayer structure, thus changing the enzyme recognition for impeding the catalytic process of the $\mathrm{CrGH}$ in vitro. At present, the related protein homology modeling of $\mathrm{CrGH}$ has a lack of valid templates supported by experimental data. Therefore, crystal analysis and molecular docking of $\mathrm{CrGH}$ will be investigated in a future study to dissect the catalytic mechanism. In this study, the multi-targeting subcellular localizations of $\mathrm{CrGH}$ indicated post-translational modification is likely essential for the authentic activity of $\mathrm{CrGH}$ in vivo. Therefore, we will also use the recombinant protein expressed by S. cerevisiae INVSC1 for future study. On the other hand, it could not be excluded that the CrGH may function as GGGT in vivo. A recent study confirmed that SFR2 coding AtGGGT localized at the outer chloroplast envelope membranes of Arabidopsis can stabilize the chloroplast membrane structure under freezing stress condition owing to its galactosyltransferase activity, with the formation of oligogalactolipids and DAG by transferring the galactosyl moiety from one MGDG molecule onto the other galactolipid acceptor [27]. In addition, AtSFR2 displayed a specific hydrolytic activity against $\beta$-glucosidase in vitro [39]. Although previous studies indicated that $C$. reinhardtii does not possess the ortholog of GGGT [28], it is necessary to conduct thorough in vivo and in vitro investigations to test whether $\mathrm{CrGH}$ could function as GGGT.

\section{Conclusions}

An algal LB-associated putative glycosyl hydrolase encoding gene was cloned, and the corresponding recombinant protein showed typical galactosyl hydrolase activity in vitro. The in vivo function of $\mathrm{CrGH}$ was found to be involved in TAG biosynthesis and turnover of galactolipids through characterizing an $\mathrm{CrGH}$ insertion mutant. In addition, the upregulation of $\mathrm{CrGH}$ at both a gene expression and protein level was observed under $\mathrm{HL}$ 
conditions. In summary, this study uncovered a novel paradigm mediating the conversion of the photosynthetic membranes to the storage lipids. The physiological functions of $\mathrm{CrGH}$ under other abiotic and biotic stress conditions remain to be investigated in the future.

\section{Materials and Methods}

\subsection{Strains and Growth Conditions}

C. reinhardtii cc- $400 \mathrm{cw} 15 \mathrm{mt}+$, cc4533, and $\mathrm{CrGH}$ deletion mutant were obtained from the Chlamydomonas Resource Center (http://chlamycollection.org/, Minnesota University). The algal cell cultures were grown in Tris-acetate-phosphate (TAP) medium at $23{ }^{\circ} \mathrm{C}$ under a continuous illumination of $50 \mu \mathrm{mol}$ photons $/\left(\mathrm{m}^{2} \cdot \mathrm{s}\right)$. For induction of TAG accumulation, the algal cells in the exponential growth phase grown under low light (LL) conditions at $50 \mu \mathrm{mol}$ photons $/\left(\mathrm{m}^{2} \cdot \mathrm{s}\right)$ were harvested by centrifugation at $3000 \times g$ for 5 min, resuspended in fresh Sueoka's high salt medium (HSM) at a starting cell density of $2 \times 10^{6}$ cells $/ \mathrm{mL}$, and then subjected to the high-light (HL) conditions, corresponding to the illumination of $200 \mu \mathrm{mol}$ photons $/\left(\mathrm{m}^{2} \cdot \mathrm{s}\right)$. Cell aliquots were collected at defined time intervals. All the cell cultures were grown on an orbital shaker (NBS Innova 44R, Eppendorf, Germany) with continuous shaking at $120 \mathrm{rpm}$.

\subsection{Bioinformatics Analysis}

To identify the gene coding for the glycosyl hydrolase identified in LBs, a BLASTP search of the C. reinhardtii genome database (https:/ / phytozome.jgi.doe.gov/pz/portal. $\mathrm{html}$ ) was performed by using the reported protein sequence (Chlre V 3.0 Protein ID:169029) as the query. The gene annotated as glycosyl hydrolase $(\mathrm{CrGH}$, annotation number: Cre03.g171050.t1.1) was obtained. The cDNA of $\mathrm{CrGH}$ was amplified by PCR from the cDNA library with the primers $\mathrm{CrGH}-\mathrm{F} / \mathrm{R}$ (Table S1). The PCR fragment were then cloned into the pEASY-Blunt simple cloning vector (Transgen, China) for sequencing. The protein transmembrane helices, putative transit peptide, and signal sequences were identified by using TMHMM Server v. 2.0, ChloroP 1.1, and SignalP 4.0, respectively. In addition, the software TargetP 1.1 (http:/ / www.cbs.dtu.dk/services/TargetP-1.1/index.php), WoLF PSORT (https:/ / wolfpsort.hgc.jp/), and ProtComp (http:/ /www.softberry.com/) were used to predict the subcellular localization. The amino acid sequences were aligned by DNAMAN software, and consensus sequences were highlighted using BOXSHAD (https://embnet.vital-it.ch/software/BOX_form.html).

\subsection{Heterologous Expression of the Recombinant $\mathrm{CrGH}$ in Escherichia coli}

The full-length $\mathrm{CrGH}$ coding sequence was amplified from the $\mathrm{pEASY} / \mathrm{CrGH}$ plasmid with the primers $\mathrm{CrGH}$-mbp-linker-F/R (Table S1) and was then constructed into the pMALc5 $x$ vector (NEB, Ipswich, MA, USA) containing the maltose binding protein (MBP) tag. Escherichia coli BL21 (DE3) cells were transformed with the constructed plasmids for protein expression. The single transformation was inoculated to $10 \mathrm{~mL}$ of Luria-Bertani (LB) medium with ampicillin $(100 \mu \mathrm{g} / \mathrm{mL}$ final concentration $)$ and grown at $37^{\circ} \mathrm{C}$ overnight on an orbital shaker at a speed of $220 \mathrm{rpm}$. Approximately $0.5 \mathrm{~mL}$ of the cell culture was added to $50 \mathrm{~mL}$ of LB medium and grown at $37^{\circ} \mathrm{C}$ for $3 \mathrm{~h}$. When the $\mathrm{OD}_{600}$ reached about 2 , the cells were cultured at $30{ }^{\circ} \mathrm{C}$ for $16 \mathrm{~h}$ with the addition of isopropyl- $\beta$-Dthiogalactopyranoside (IPTG, $0.4 \mathrm{mM}$ final concentration). The cells were harvested by centrifugation at $5000 \times \mathrm{g}$ for $10 \mathrm{~min}$ at $4{ }^{\circ} \mathrm{C}$. Then, the pellets were frozen in liquid $\mathrm{N}_{2}$, and stored at $-80^{\circ} \mathrm{C}$ until use.

Purification of the recombinant protein was performed as instructed by the manufacturer's instructions (NEBExpress ${ }^{\circledR}$ MBP Fusion and Purification System, NEB, Ipswich, MA, USA). Briefly, the harvested E. coli cell pellets were resuspended in $25 \mathrm{~mL}$ of the column buffer containing $20 \mathrm{mM}$ Tris- $\mathrm{HCl}$ (pH 7.4), $200 \mathrm{mM} \mathrm{NaCl}, 1 \mathrm{mM}$ EDTA, $1 \mathrm{mM}$ DTT, and $1 \times$ cocktail proteinase inhibitors (Roche, Switzerland). The mixture was sonicated to lyse cells. Lysates were centrifuged at $20,000 \times \mathrm{g}$ for $15 \mathrm{~min}$ at $4{ }^{\circ} \mathrm{C}$ and the supernatant was mixed well with amylase resin (NEB, Ipswich, MA, USA) overnight with rotation at 
a low speed. The mixture was loaded onto a $2.5 \times 10 \mathrm{~cm}$ column, and was washed with 12 column volumes of column buffer. The target protein was eluted by column buffer with $10 \mathrm{mM}$ maltose. The purified protein was checked after separation on SDS-PAGE gel. Protein concentration was determined with a $\mathrm{CB}-\mathrm{X}^{\mathrm{TM}}$ Protein Assay kit (GBioscience, St. Louis, MO, USA).

\subsection{Antisera Production and Purification}

The PCR fragments of $\mathrm{CrGH}$ were digested with EcoR I/Xho I, and then ligated with the enzymatic digested pGEX-4T-1 vector (GBiosciences, St. Louis, MO, USA). The induced cell pellets of E. coli BL21 (DE3) strains harboring the pGEX-4T-1-CrGH constructs were disrupted by sonication to isolate the inclusion bodies, and the recombinant $\mathrm{CrGH}$ in the form of inclusion bodies were directly recovered from the SDS-PAGE and were used as the antigen to raise antiserum in rabbits by following the standard protocol (ABclonal Biotechnology Co., Ltd., Wuhan, China). The antigen was prepared with Freund's adjuvant and then injected into rabbits with three additional boosts. The final purified antigen-specific polyclonal antibodies were used as the primary antibody for immuno-blotting analysis.

\subsection{In Vitro Enzymatic Assay with the Recombinant CrGH}

Galactosyl hydrolase activity of the recombinant $\mathrm{CrGH}$ protein was assayed by using a $\beta$-Galactosidase kit (Solarbio, Beijing, China) according to the instructions. In a $500 \mu \mathrm{L}$ reaction, different quantities of the purified protein $(20,100$, and $500 \mu \mathrm{g})$ were mixed with the substrate of $3 \mu \mathrm{M}$ o-nitrophenyl- $\beta$-D-galactoside (ONPG) in $30 \mathrm{mM}$ magnesium chloride solution buffer ( $\mathrm{pH}$ 7.3) for incubation at $37^{\circ} \mathrm{C}$ for $15 \mathrm{~min}$. Then, the reactions were stopped by addition of $300 \mu \mathrm{L}$ of $0.4 \mathrm{M}$ sodium carbonate and the o-nitrophenol produced via the hydrolytic reaction was measured according to its optical absorbance at $400 \mathrm{~nm}$. The $\beta$-galactosidase from E. coli (Sigma-Aldrich, St. Louis, MO, USA) was used as a positive control. For the enzymatic kinetics determination, the different gradient concentrations of o-nitrophenyl- $\beta$-D-galactoside $(0.15,0.375,0.75,1.5,2.25,3,7.5,12,18$, 24 , and $30 \mu \mathrm{mol}$ ) were incubated with approximately $20 \mu \mathrm{g}$ of the purified CrGH protein in the reaction system. All the experiments were performed with at least three replicates. Values are presented as means \pm SD. The enzyme kinetics analyses were performed using Microsoft Excel for curve-fitting.

In addition, we used both commercial and purified galactolipids of C. reinhardtii for the in vitro assay, as mentioned above. The commercial galactolipids included: the MGDG mixture (Avanti Polar Lipids, Alabaster, AL, USA) consisting of $66.8 \%$ of MGDG 16:3-18:3, 14.1\% of MGDG 18:3-18:3, 12.9\% of MGDG 16:3-18:2,3.2\% of MGDG 18:2-18:3, and $3.0 \%$ of MGDG 16:1-18:3; and DGDG mixture (Avanti Polar Lipids, Alabaster, Alabama, USA) consisting of $44.5 \%$ of DGDG 18:3-18:3, 21.3\% of DGDG 16:3-18:3, 10.7\% of DGDG 18:2-18:3, 9.7\% of DGDG 16:0-18:3, 7.0\% of DGDG 16:3-18:2, and 6.9\% of DGDG 16:1-18:3. The MGDG and DGDG of C. reinhardt $i$ were also extracted and purified with thinchromatography chromatography using chloroform/hexane/tetrahydrofuran/isopropanol/ water (50:100:1:80:2, $v / v / v / v / v)$ as the solvent system. The developed TLC plates were air-dried and sprayed uniformly with solid iodine at room temperature for $10 \mathrm{~min}$. The MGDG and DGDG spots were scraped from the TLC plates and then dissolved in chloroform/methanol $(1: 1, v / v)$ solutions. The solvents were then evaporated under nitrogen stream. Lipid samples were stored at $-80^{\circ} \mathrm{C}$ prior to use.

\subsection{RNA Extraction and Real-Time Fluorescent Quantitative PCR}

Total RNAs were extracted using TransZol Up reagent (TransGen, Beijing, China). The cDNA was generated through reverse transcription using EasyScript One-Step cDNA Removal and cDNA Synthesis SuperMix kit (TransGen, Beijing, China). Quantitative realtime PCR was performed with a LightCycler ${ }^{\circledR} 480$ System according to the manufacturer's instructions and using the LightCycler ${ }^{\circledR}$ Multiplex Masters (Roche, Basel, Switzerland) 
with the primers CrGH-qPCR-F/R (Table S1). The $\alpha$-tubulin gene was used as the internal reference.

\subsection{Verification of the Mutant Defective in $\mathrm{CrGH}$}

A Chlamydomonas mutant (LMJ.RY0402.088610) generated by electroporation of a DNA cassette (CIB1) conferring resistance to paromomycin into Chlamydomonas strain cc4533 [40] was purchased from the Chlamydomonas Resource Center. To verify the inserted mutation defective in $\mathrm{CrGH}$, the genomic DNA of LMJ.RY0402.088610 was extracted using an EasyPure ${ }^{\circledR}$ Plant Genomic DNA Kit (TransGen, Beijing, China). Two pairs of primers (primers G1/C1 and primers G2/C2, Table S1) were utilized to amplify the cassette-genome junction on both sides of each insertion site, as indicated by the flanking sequences [41]. The $25 \mu \mathrm{L}$ PCR reaction mixtures contained $2.0 \mu \mathrm{L} 2.5 \mathrm{mM}$ dNTPs, $16 \mu \mathrm{L}$ of nuclease-free water, $0.5 \mu \mathrm{L}$ of each primer at $10 \mu \mathrm{M}, 0.5 \mu \mathrm{L}$ of $50 \mathrm{ng} / \mu \mathrm{L}$ C. reinhardtii genomic DNA, $0.5 \mu \mathrm{L}$ TransStart ${ }^{\circledR}$ FastPfu DNA polymerase, and $5 \mu \mathrm{L} 5 \times$ TransStart $^{\circledR}$ FastPfu Buffer (TransGen, Beijing, China). PCR amplification parameters were: $3 \mathrm{~min}$ at $95^{\circ} \mathrm{C}$, 35 cycles of $30 \mathrm{~s}$ at $95^{\circ} \mathrm{C}, 30 \mathrm{~s}$ at $54{ }^{\circ} \mathrm{C}, 45 \mathrm{~s}$ at $72{ }^{\circ} \mathrm{C}$, followed by a final extension of $5 \mathrm{~min}$ at $72{ }^{\circ} \mathrm{C}$. The PCR amplification products were purified for sequencing. The resulting sequences were aligned against the $C$. reinhardtii genome sequence from Phytozome v5.3.

\subsection{Lipid Extraction and Fatty Acids Profiling}

C. reinhardtii cells were collected by centrifugation at $3000 \times g$ for $5 \mathrm{~min}$ and the pellets were lyophilized. Total lipids were extracted according to the Bligh and Dyer method [42] and separated on a silica thin layer chromatography (TLC) plate (Merck, Germany) using petroleum ether/ethyl ether/acetic acid (70:30:1, $v / v / v)$ as the solvent system. For the visualization of the separated glycerides, the developed TLC plates were air-dried and sprayed uniformly with solid iodine at room temperature for $10 \mathrm{~min}$. The TAG spots were scraped from the TLC plates and then trans-esterified to the fatty acid methyl esters for gas chromatography-mass spectrometry analysis by using an Agilent 7890B gas chromatograph coupled with 59977A mass spectrometry (GC-MS, Santa Clara, CA, USA), as previously described [9].

\subsection{Quantitatively Analysis of the Membrane Lipids with Electrospray Ionization Mass Spectrometry (ESI/MS)}

Membrane lipids analyses were performed according to the previously described lipidomic method [9] with modifications. Lipidomes analyses were performed on a triple quadrupole MS/MS (Xevo TQ-S, Waters, Milford, MA, USA) with electrospray ionization (ESI) source coupled with an Acquity Ultra-Performance Liquid Chromatography (UPLC) system (Waters, Milford, MA, USA). The extracted lipids were dissolved in $1 \mathrm{~mL}$ chloroform/methanol $(1: 1, v / v)$ and then were mixed with internal standards (ISTDs), including MGDG 18:0/18:0, DGDG 18:0/18:0, 1, 2-diacylglyceryl-3-O-4'-( $N, N$, $N$-trimethyl)-homoserine (DGTS) 16:0/16:0 d9, phosphatidylglycerol (PG) 17:0/20:4, phosphatidylethanolamine (PE) 17:0/14:1, and phosphatidylinositol (PI) 17:0/20:4. The MGDG mixture standard containing MGDG 16:1/18:3, MGDG 16:3/18:2, and MGDG 16:3/18:3; DGDG mixture standard containing DGDG 16:0/18:3, DGDG 16:1/18:3, DGDG 16:3/18:2, and DGDG 16:3/18:3; DGTS 16:0/16:0, PG 16:0/18:1, PG 18:0/18:1, PE 18:0/18:1, PI 18:1/18:1, and sulfoquinovosyldiacylglycerol (SQDG) 16:0/18:3 were used as external standards (ETSDs) for the corresponding classes of membrane lipids. All lipid standards were purchased from Avanti Polar Lipids Ltd. (Alabaster, AL, USA) except for MGDG 18:0/18:0 and DGDG 18:0/18:0, which were purchased from Matreya LLC (State College PA, USA). For absolute quantification, ESTDs were titrated relative to a constant amount of ISTD to establish the correlation between the ratio of the analyte signal to the ISTD signal and the ratio of their concentrations. In this study, multiple reaction monitoring (MRM) was employed for quantitative analysis. All experiments were repeated three times on different biological samples, each of which contained three technical replicates. 


\subsection{Preparation of Subcellular Compartments}

To obtain cellular organelles extracts of $C$. reinhardtii, four liters of cc 400 cell cultures during the logarithmic period was harvested by centrifugation at $3000 \times g$ for $5 \mathrm{~min}$ at $4{ }^{\circ} \mathrm{C}$ and washed with ice-cold PBS buffer. Cell pellets were used for organelle fraction extraction. Mitochondria and ER membranes were isolated as previously described [43,44], respectively. Chloroplast envelope membranes and thylakoid membranes were isolated as previously described [45-47] with some modifications. The pellets were resuspended in breaking buffer containing $0.3 \mathrm{M}$ sorbitol and $50 \mathrm{mM}$ HEPES $(\mathrm{pH}=7.5)$, and $2 \mathrm{mM}$ EDTANa $_{2}(\mathrm{pH}=8.0), 1 \mathrm{mM} \mathrm{MgCl}_{2}$, and $1 \times$ cocktail protease inhibitors to a concentration of $10^{8}$ cells $/ \mathrm{mL}$, and the diluted cells were rapidly drawn into the syringe with a 27-gauge needle and passed through the needle at a flow rate of $0.25 \mathrm{~mL} / \mathrm{s}$. The cell homogenates were centrifuged at $1000 \times g$ for $5 \mathrm{~min}$ to pellet chloroplasts and unbroken cells. Pellets were resuspended in chloroplast lysis buffer containing $50 \mathrm{mM}$ Tris- $\mathrm{HCl}(\mathrm{pH}=7.5)$ and $2 \mathrm{mM} \mathrm{MgCl}_{2}$, and homogenized with a Potter-Elvehjem tissue grinder. The homogenates were layered onto a sucrose gradient containing $0.9 \mathrm{M} / 0.6 \mathrm{M}$ sucrose in the chloroplast lysis buffer and centrifuged at $10,000 \times g$ for $60 \mathrm{~min}$ at $4{ }^{\circ} \mathrm{C}$. The membrane fractions at the interface of $0.9 \mathrm{M} / 0.6 \mathrm{M}$ sucrose were collected as the chloroplast envelope membranes. The pellet was further resuspended in $1.8 \mathrm{M}$ sucrose in buffer A containing $50 \mathrm{mM}$ Tris- $\mathrm{HCl}$ (pH 7.5) and $10 \mathrm{mM} \mathrm{EDTANa}_{2}$ ( $\mathrm{pH} \mathrm{8.0)}$, and homogenized with a Potter-Elvehjem tissue grinder. The homogenates were layered onto a sucrose gradient containing $1.3 \mathrm{M} / 0.6 \mathrm{M}$ sucrose in buffer A and centrifuged at $100,000 \times g$ for $60 \mathrm{~min}$. Thylakoid membranes floating on the $1.3 \mathrm{M}$ sucrose were collected.

\subsection{Immunoblotting Analysis}

The isolated organelle fractions were resuspended in a mixture of $60 \mu \mathrm{L}$ of buffer $\mathrm{B}$ containing $0.1 \mathrm{M}$ dithiothreitol and $0.1 \mathrm{M} \mathrm{Na}_{2} \mathrm{CO}_{3}$, and $40 \mu \mathrm{L}$ of buffer $\mathrm{C}$ containing $30 \%$ $(w / v)$ sucrose and $5 \%(w / v)$ SDS, and vortexed at $3000 \mathrm{rpm}$ for $30 \mathrm{~min}$. Insoluble proteins were removed by centrifugation at $12,000 \times g$ for $10 \mathrm{~min}$. The protein concentration was measured using a CB-X protein assay kit (GBiosciences, St. Louis, MO, USA). Proteins were loaded onto $12 \%$ SDS-PAGE gels and transferred to a nitrocellulose membrane. Antibodies against $\mathrm{CrGH}$ (prepared by ABclonal Biotechnology Co., Ltd., Wuhan, China), Toc34 (AS07238, Agrisera), Bip (AS09481, Agrisera), Aoxi (AS06152, Agrisera), PsbA/D1 (AS05084, Agrisera) and $\alpha$-Tubulin (AS10680, Agrisera) were used at 1:1000, 1:10000, 1:2000, 1:10000, 1:10000, and 1:1000 dilutions, respectively. Secondary anti-rabbit antibodies (1706515, Bio-Rad) and anti-mouse antibodies (1706516, Bio-Rad) were both used at 1:1000 dilution. Immunoblotting signals were visualized with an enhanced chemiluminescence (ECL) assay kit (Vazyme, China) according to the manufacturer's protocol.

Supplementary Materials: The following are available online at https:/ /www.mdpi.com/article/10 .3390 / plants10040675/s1, Figure S1: The growth rates of the $\mathrm{CrGH}$ insertion mutant and the wild type cc4533 strains grown under various culturing conditions. a and b represented the cell growth and dry weight of $C$. reinhardtii under the normal culture and high light stress conditions, respectively. The line chart represented the cells number and the histogram represented cells dry weight. Figure S2: The extraplastidic membrane lipids contents in the $\mathrm{CrGH}$ insertion mutant and wild type cc4533. a. The PE contents. b. The DGTS contents. Data are presented as average \pm SD $(n=3)$. Table S1: Primers used for $\mathrm{CrGH}$ gene cloning and PCR analysis. Table S2: The subcellular location prediction of CrGH by WoLF PSORT.

Author Contributions: X.G. performed bioinformatics analyses, molecular cloning, recombinant protein expression, enzymatic assays and lipidomics experiments. X.W. carried out the protein subcellular localiza-tion experiment. L.C. optimized the enzymatic assays. Y.L. analyzed the data of the TAG con-tents. X.G., Q.H. and D.H. analyzed the data and wrote the article.

Funding: This research was funded by The National Key R\&D Program of China (2018YFA0902500) and State Key Laboratory of Freshwater Ecology and Biotechnology, Institute of Hydrobiology, Chinese Academy of Sciences (2019FBZ06). 
Data Availability Statement: All datasets generated and/or analyzed during this study are available from the corresponding author on reasonable request.

Acknowledgments: We thank Rongli Miao for her assistance in the protein subcellular localization experiment.

Conflicts of Interest: The authors declare no conflict of interest.

\section{References}

1. Wijffels, R.H.; Barbosa, M.J.; Eppink, M.H.M. Microalgae for the production of bulk chemicals and biofuels. Biofuels Bioprod. Biorefin. Biofpr. 2010, 4, 287-295. [CrossRef]

2. $\mathrm{Hu}, \mathrm{Q} . ;$ Sommerfeld, M.; Jarvis, E.; Ghirardi, M.; Posewitz, M.; Seibert, M.; Darzins, A. Microalgal triacylglycerols as feedstocks for biofuel production: Perspectives and advances. Plant J. Cell Mol. Biol. 2008, 54, 621-639. [CrossRef] [PubMed]

3. Li-Beisson, Y.; Beisson, F.; Riekhof, W. Metabolism of acyl-lipids in Chlamydomonas reinhardtii. Plant J. 2015, 82, 504-522. [CrossRef] [PubMed]

4. Liu, J.; Han, D.; Yoon, K.; Hu, Q.; Li, Y. Characterization of type 2 diacylglycerol acyltransferases in Chlamydomonas reinhardtii reveals their distinct substrate specificities and functions in triacylglycerol biosynthesis. Plant J. 2016, 86, 3-19. [CrossRef] [PubMed]

5. Chisti, Y. Biodiesel from microalgae. Biotechnol. Adv. 2007, 25, 294-306. [CrossRef]

6. Merchant, S.S.; Kropat, J.; Liu, B.; Shaw, J.; Warakanont, J. TAG, you're it! Chlamydomonas as a reference organism for understanding algal triacylglycerol accumulation. Curr. Opin. Biotechnol. 2012, 23, 352-363. [CrossRef]

7. Boyle, N.R.; Page, M.D.; Liu, B.; Blaby, I.K.; Casero, D.; Kropat, J.; Cokus, S.J.; Hong-Hermesdorf, A.; Shaw, J.; Karpowicz, S.J.; et al. Three Acyltransferases and Nitrogen-responsive Regulator Are Implicated in Nitrogen Starvation-induced Triacylglycerol Accumulation in Chlamydomonas. J. Biol. Chem. 2012, 287, 15811-15825. [CrossRef]

8. La Russa, M.; Bogen, C.; Uhmeyer, A.; Doebbe, A.; Filippone, E.; Kruse, O.; Mussgnug, J.H. Functional analysis of three type-2 DGAT homologue genes for triacylglycerol production in the green microalga Chlamydomonas reinhardtii. J. Biotechnol. 2012, 162, 13-20. [CrossRef]

9. Yoon, K.; Han, D.; Li, Y.; Sommerfeld, M.; Hu, Q. Phospholipid:diacylglycerol acyltransferase is a multifunctional enzyme involved in membrane lipid turnover and degradation while synthesizing triacylglycerol in the unicellular green microalga Chlamydomonas reinhardtii. Plant Cell 2012, 24, 3708-3724. [CrossRef]

10. Kennedy, E.P. Biosynthesis of complex lipids. Fed. Proc. 1961, 20, 934-940.

11. Duarte-Coello, M.E.; Herrera-Valencia, V.A.; Echevarria-Machado, I.; Casais-Molina, M.L.; Peraza-Echeverria, S. Molecular cloning and functional characterization of two glycerol-3-phosphate acyltransferases from the green microalga Chlamydomonas reinhardtii. Phycol. Res. 2019, 67, 102-111. [CrossRef]

12. Yamaoka, Y.; Achard, D.; Jang, S.; Legéret, B.; Kamisuki, S.; Ko, D.; Schulz-Raffelt, M.; Kim, Y.; Song, W.Y.; Nishida, I.; et al. Identification of a Chlamydomonas plastidial 2-lysophosphatidic acid acyltransferase and its use to engineer microalgae with increased oil content. Plant Biotechnol. J. 2016, 14, 2158-2167. [CrossRef]

13. Kim, Y.; Terng, E.L.; Riekhof, W.R.; Cahoon, E.B.; Cerutti, H. Endoplasmic reticulum acyltransferase with prokaryotic substrate preference contributes to triacylglycerol assembly in Chlamydomonas. Proc. Natl. Acad Sci. USA 2018, 115, 1652-1657. [CrossRef]

14. Harwood, J.L.; Jones, A.L. Lipid Metabolism in Algae. Adv. Bot. Res. 1989, 16, 1-53. [CrossRef]

15. Block, M.A.; Dorne, A.J.; Joyard, J.; Douce, R. Preparation and characterization of membrane fractions enriched in outer and inner envelope membranes from spinach chloroplasts. II. Biochemical characterization. J. Biol. Chem. 1983, 258, 13281-13286. [CrossRef]

16. Jordan, P.; Fromme, P.; Witt, H.T.; Klukas, O.; Saenger, W.; Krauss, N. Three-dimensional structure of cyanobacterial photosystem I at 2.5 A resolution. Nature 2001, 411, 909-917. [CrossRef]

17. Loll, B.; Kern, J.; Saenger, W.; Zouni, A.; Biesiadka, J. Towards complete cofactor arrangement in the 3.0 A resolution structure of photosystem II. Nature 2005, 438, 1040-1044. [CrossRef]

18. Guskov, A.; Kern, J.; Gabdulkhakov, A.; Broser, M.; Zouni, A.; Saenger, W. Cyanobacterial photosystem II at 2.9-A resolution and the role of quinones, lipids, channels and chloride. Nat. Struct. Mol. Biol. 2009, 16, 334-342. [CrossRef]

19. Umena, Y.; Kawakami, K.; Shen, J.R.; Kamiya, N. Crystal structure of oxygen-evolving photosystem II at a resolution of $1.9 \AA$ A. Nature 2011, 473, 55-60. [CrossRef]

20. Kurisu, G.; Zhang, H.; Smith, J.L.; Cramer, W.A. Structure of the cytochrome b6f complex of oxygenic photosynthesis: Tuning the cavity. Science 2003, 302, 1009-1014. [CrossRef]

21. Stroebel, D.; Choquet, Y.; Popot, J.L.; Picot, D. An atypical haem in the cytochrome b(6)f complex. Nature 2003, 426, 413-418. [CrossRef]

22. Seiwert, D.; Witt, H.; Janshoff, A.; Paulsen, H. The non-bilayer lipid MGDG stabilizes the major light-harvesting complex (LHCII) against unfolding. Sci. Rep. 2017, 7, 5158. [CrossRef]

23. Sakurai, I.; Mizusawa, N.; Wada, H.; Sato, N. Digalactosyldiacylglycerol Is Required for Stabilization of the Oxygen-Evolving Complex in Photosystem II. Plant Physiol. 2007, 145, 1361-1370. [CrossRef]

24. Fujii, S.; Kobayashi, K. Digalactosyldiacylglycerol Is Essential for Organization of the Membrane Structure in Etioplasts. Plant Physiol. 2018, 177, 1487-1497. [CrossRef] 
25. Moellering, E.R.; Benning, C. RNA interference silencing of a major lipid droplet protein affects lipid droplet size in Chlamydomonas reinhardtii. Eukaryot. Cell 2010, 9, 97-106. [CrossRef]

26. Li, X.; Moellering, E.R.; Liu, B.; Johnny, C.; Fedewa, M.; Sears, B.B.; Kuo, M.H.; Benning, C. A galactoglycerolipid lipase is required for triacylglycerol accumulation and survival following nitrogen deprivation in Chlamydomonas reinhardtii. Plant Cell 2012, 24, 4670-4686. [CrossRef]

27. Moellering, E.R.; Muthan, B.; Benning, C. Freezing Tolerance in Plants Requires Lipid Remodeling at the Outer Chloroplast Membrane. Science 2010, 330, 226-228. [CrossRef]

28. Fan, J.; Andre, C.; Xu, C. A chloroplast pathway for the de novo biosynthesis of triacylglycerol in Chlamydomonas reinhardtii. FEBS Lett. 2011, 585, 1985-1991. [CrossRef]

29. Bréhélin, C.; Kessler, F. The plastoglobule: A bag full of lipid biochemistry tricks. Photochem. Photobiol. 2008, 84, 1388-1394. [CrossRef]

30. Goold, H.; Beisson, F.; Peltier, G.; Li-Beisson, Y. Microalgal lipid droplets: Composition, diversity, biogenesis and functions. Plant Cell Rep. 2015, 34, 545-555. [CrossRef]

31. James, G.O.; Hocart, C.H.; Hillier, W.; Chen, H.; Kordbacheh, F.; Price, G.D.; Djordjevic, M.A. Fatty acid profiling of Chlamydomonas reinhardtii under nitrogen deprivation. Bioresour. Technol. 2011, 102, 3343-3351. [CrossRef] [PubMed]

32. Nguyen, H.M.; Baudet, M.; Cuiné, S.; Adriano, J.M.; Barthe, D.; Billon, E.; Bruley, C.; Beisson, F.; Peltier, G.; Ferro, M.; et al. Proteomic profiling of oil bodies isolated from the unicellular green microalga Chlamydomonas reinhardtii: With focus on proteins involved in lipid metabolism. Proteomics 2011, 11, 4266-4273. [CrossRef] [PubMed]

33. Tsai, C.H.; Zienkiewicz, K.; Amstutz, C.L.; Brink, B.G.; Warakanont, J.; Roston, R.; Benning, C. Dynamics of protein and polar lipid recruitment during lipid droplet assembly in Chlamydomonas reinhardtii. Plant J. Cell Mol. Biol. 2015, 83, 650-660. [CrossRef] [PubMed]

34. Martin, G.J.; Hill, D.R.; Olmstead, I.L.; Bergamin, A.; Shears, M.J.; Dias, D.A.; Kentish, S.E.; Scales, P.J.; Botté, C.Y.; Callahan, D.L. Lipid profile remodeling in response to nitrogen deprivation in the microalgae Chlorella sp. (Trebouxiophyceae) and Nannochloropsis sp. (Eustigmatophyceae). PLoS ONE 2014, 9, e103389. [CrossRef]

35. Shipley, G.G.; Green, J.P.; Nichols, B.W. The phase behavior of monogalactosyl, digalactosyl, and sulphoquinovosyl diglycerides. Biochim. Biophys. Acta 1973, 311, 531-544. [CrossRef]

36. Lavell, A.A.; Benning, C. Cellular Organization and Regulation of Plant Glycerolipid Metabolism. Plant Cell Physiol. 2019, 60, 1176-1183. [CrossRef]

37. Martin, S.; Parton, R.G. Lipid droplets: A unified view of a dynamic organelle. Nat. Rev. Mol. Cell Biol. 2006, 7, 373-378. [CrossRef]

38. Goodson, C.; Roth, R.; Wang, Z.T.; Goodenough, U. Structural correlates of cytoplasmic and chloroplast lipid body synthesis in Chlamydomonas reinhardtii and stimulation of lipid body production with acetate boost. Eukaryot. Cell 2011, 10, 1592-1606. [CrossRef]

39. Thorlby, G.; Warren, F.G. The SENSITIVE TO FREEZING2 Gene, Required for Freezing Tolerance in Arabidopsis thaliana, Encodes a $\beta$-Glucosidase. Plant Cell 2004, 16, 2192-2203. [CrossRef]

40. Li, X.; Patena, W.; Fauser, F.; Jinkerson, R.E. A genome-wide algal mutant library and functional screen identifies genes required for eukaryotic photosynthesis. Nat. Genet. 2019, 51, 627-635. [CrossRef]

41. Zhang, R.; Patena, W.; Armbruster, U.; Gang, S.S.; Blum, S.R.; Jonikas, M.C. High-Throughput Genotyping of Green Algal Mutants Reveals Random Distribution of Mutagenic Insertion Sites and Endonucleolytic Cleavage of Transforming DNA. Plant Cell 2014, 26, 1398-1409. [CrossRef]

42. Bligh, E.G.; Dyer, W.J. A RAPID METHOD OF TOTAL LIPID EXTRACTION AND PURIFICATION. Can. J. Biochem. Physiol. 1959, 37, 911-917. [CrossRef]

43. Eriksson, M.; Gardestrom, P.; Samuelsson, G. Isolation, Purification, and Characterization of Mitochondria from Chlamydomonas reinhardtii. Plant Physiol. 1995, 107, 479-483. [CrossRef]

44. Bessoule, J.J.; Testet, E.; Cassagne, C. Synthesis of phosphatidylcholine in the chloroplast envelope after import of lysophosphatidylcholine from endoplasmic reticulum membranes. Eur. J. Biochem. 1995, 228, 490-497. [CrossRef]

45. Mendiola-Morgenthaler, L.; Eichenberger, W.; Boschetti, A. Isolation of chloroplast envelopes from Chlamydomonas. Lipid and polypeptide composition. Plant Sci. 1985, 41, 97-104. [CrossRef]

46. Mason, C.B.; Bricker, T.M.; Moroney, J.V. A rapid method for chloroplast isolation from the green alga Chlamydomonas reinhardtii. Nat. Protoc. 2006, 1, 2227-2230. [CrossRef]

47. Chua, N.H.; Bennoun, P. Thylakoid membrane polypeptides of Chlamydomonas reinhardtii: Wild-type and mutant strains deficient in photosystem II reaction center. Proc. Natl. Acad Sci. USA 1975, 72, 2175-2179. [CrossRef] 